\title{
Second Malignant Neoplasms and Cardiovascular Disease Following Radiotherapy
}

Lois B. Travis, Andrea K. Ng, James M. Allan, Ching-Hon Pui, Ann R. Kennedy, X. George Xu, James A. Purdy, Kimberly Applegate, Joachim Yahalom, Louis S. Constine, Ethel S. Gilbert, John D. Boice Jr

Manuscript received May 24, 2011; revised November 21, 2011; accepted November 30, 2011.

Correspondence to: Lois B. Travis, MD, ScD, Rubin Center for Cancer Survivorship and Department of Radiation Oncology, James P. Wilmot Cancer Center, University of Rochester Medical Center, 265 Crittenden Blvd, CU 420318, Rochester, NY 14642 (e-mail: Lois_Travis@URMC.Rochester.edu).

Second malignant neoplasms (SMNs) and cardiovascular disease (CVD) are among the most serious and life-threatening late adverse effects experienced by the growing number of cancer survivors worldwide and are due in part to radiotherapy. The National Council on Radiation Protection and Measurements (NCRP) convened an expert scientific committee to critically and comprehensively review associations between radiotherapy and SMNs and CVD, taking into account radiobiology; genomics; treatment (ie, radiotherapy with or without chemotherapy and other therapies); type of radiation; and quantitative considerations (ie, dose-response relationships). Major conclusions of the NCRP include: 1) the relevance of older technologies for current risk assessment when organ-specific absorbed dose and the appropriate relative biological effectiveness are taken into account and 2) the identification of critical research needs with regard to newer radiation modalities, dose-response relationships, and genetic susceptibility. Recommendation for research priorities and infrastructural requirements include 1) long-term largescale follow-up of extant cancer survivors and prospectively treated patients to characterize risks of SMNs and CVD in terms of radiation dose and type; 2 ) biological sample collection to integrate epidemiological studies with molecular and genetic evaluations; 3) investigation of interactions between radiotherapy and other potential confounding factors, such as age, sex, race, tobacco and alcohol use, dietary intake, energy balance, and other cofactors, as well as genetic susceptibility; 4) focusing on adolescent and young adult cancer survivors, given the sparse research in this population; and 5) construction of comprehensive risk prediction models for SMNs and CVD to permit the development of follow-up guidelines and prevention and intervention strategies.

J Natl Cancer Inst 2012;104:357-370

Advances in cancer therapy, early detection, and supportive care have contributed to steady gains in the 5 -year relative survival rate for all cancers combined, which reached $66.0 \%$ for patients diagnosed during 1999-2006 (1). Commensurately, the number of cancer survivors in the United States has tripled since 1971 and is growing by $2 \%$ each year. As of 2007 , there were approximately 12 million men and women in the United States - approximately $3.5 \%$ of the US population - with a history of cancer (1). For many patients, these gains in survival have come at the price of serious treatment-associated late adverse effects.

Radiation remains a cornerstone of successful cancer treatment, with $50 \%$ of all patients estimated to receive radiotherapy (2). Second malignant neoplasms (SMNs) and cardiovascular disease (CVD) are two of the most frequent and important life-threatening adverse events associated with radiotherapy. Multiple primary cancers now account for approximately one in six of all incident cancers reported to the US Surveillance, Epidemiology, and End Results Program cancer registry (1). For patients with Hodgkin lymphoma (3), testicular cancer $(4,5)$, and certain childhood cancers (6), SMNs have emerged as an important cause of death (7). Radiotherapy-associated CVD refers to a wide spectrum of disorders and is an important cause of morbidity and mortality, most notably after thoracic radiotherapy for Hodgkin lymphoma and tangential radiotherapy for breast cancer $(8,9)$.

With the increased awareness of the adverse consequences of cancer therapy, it has become critically important to identify measures to mitigate and ameliorate these late adverse effects and to provide cancer survivors with counseling, surveillance, and supportive care. In addition, it is essential to review and balance the risks and benefits of new treatment options as they become available. Providing a research infrastructure for transdisciplinary studies of cancer survivors is also important (10). The Childhood Cancer Survivorship Study (CCSS) is a critical resource for outcome and intervention research in survivors of pediatric and adolescent cancer (11); however, a comparable research base is lacking for survivors of young adult-onset $(12,13)$ and other cancers. The expanding use of radiotherapy and development of new radiation modalities to treat cancer, coupled with improvements in longterm patient survival, underscores the importance of continuing to provide long-term risk estimates as well as additional research into the molecular underpinnings of treatment-related SMNs and CVD. Moreover, optimal screening and interventional efforts for these late adverse events must be identified (5).

To review and address the expanding burden of late adverse effects after treatment with radiation, the National Council on 
Radiation Protection and Measurements (NCRP) convened a scientific committee (ie, NCRP 1-17) of experts in radiation biology, radiation oncology, radiation physics, molecular genetics, medical oncology, pediatric oncology, cardiology, biostatistics, and epidemiology to comprehensively review radiotherapy-associated SMNs and CVD and recommend future research. This commentary provides a synthesis of the 425-page NCRP Report titled Second Primary Cancers and Cardiovascular Disease After Radiotherapy (14).

\section{Radiobiology}

The traditional paradigm for the genesis of radiation-induced adverse effects, such as cell killing and carcinogenesis, is that biological responses result from the deposition of energy in or near cellular DNA (15). Radiation then interacts with DNA, either directly via ionization or indirectly via water-derived free radicals, resulting in genetic and/or epigenetic changes that are passed on to cellular progeny and that can contribute to malignant transformation. However, based on both in vitro and in vivo studies, there is increasing realization that low doses of radiation (eg, <0.5 Gy) may also contribute to radiation-induced adverse effects such as carcinogenesis and CVD (16). Differences in cellular responses to "low" vs "high" doses of radiation have also been reported for a number of different biological endpoints, including DNA damage signaling, cell cycle checkpoint activation, DNA repair, gene and protein expression, apoptosis, and cell transformation (17). However, evidence is emerging that radiation-induced carcinogenesis may be a modifiable process (18). For example, some agents appear to be capable of either reducing or increasing the incidence of radiation-induced cancer in animal models (19-21). Given this prospect, more research is needed to identify clinical interventions to reduce late adverse effects of radiotherapy.

\section{Genetic Foundations of Late Effects of Radiotherapy}

Data from animal models and human studies demonstrate that the genotype of the host influences the risk of radiation-associated late effects. For example, patients who inherit rare pathogenic mutations in genes associated with human cancer susceptibility syndromes are predisposed to radiogenic cancers, including TP53 mutations in Li-Fraumeni syndrome (22-24), NF1 mutations in neurofibromatosis $(25,26)$, PTCH1 mutations in Gorlin syndrome (27), WT1 mutations in Wilms tumor (28-30), and RB1 mutations in retinoblastoma $(31,32)$. The increased susceptibility of mice heterozygous for the murine homologs of PTCH1 $(33,34)$, TP53 (35), and NF1 (36) to radiogenic cancers suggests the importance of these loci in human radiogenic cancers. The well-characterized roles of $B R C A 1, B R C A 2$, and $A T M$ in mediating cellular response to ionizing radiation have prompted speculation that germline mutations associated with hereditary cancer may also predispose the mutation carriers to radiogenic cancer, particularly in the contexts of contralateral breast cancer $(37,38)$ and radiotherapy for Hodgkin lymphoma $(39,40)$. However, whether pathogenic mutations in these loci confer increased susceptibility to radiogenic cancer remains controversial. Several studies found no association (39-41), whereas others provided limited evidence suggesting that specific ATM (37) and BRCA1 (38) alleles may be associated with increased risk of breast cancer, particularly in $B R C A 1$ mutation carriers exposed to radiotherapy before age 40 years $(38,42,43)$.

Many human cancer susceptibility genes that encode proteins that mediate cellular responses to ionizing radiation have a high frequency of genetic variants. For example, polymorphisms in TP53 and ATM, with corresponding amino acid changes in the respective proteins, can affect the cellular response to ionizing radiation (44-47), making them candidate risk modifiers for radiogenic cancer and other late adverse effects of radiotherapy in a polygenic disease. Targeted gene- and/or pathway-based studies investigating adverse events after low- (48-55) and high-dose (56-67) radiation exposure have identified numerous other variants, loci, and pathways that warrant further investigation; others are readily testable based on known gene-exposure interactions identified by in vitro and ex vivo studies (68). Genome-wide association studies (69-71) might identify new gene-exposure interactions; however, this approach will require large well-controlled studies with sufficient statistical power to account for various phenotypic and exposure-related risk factors. Indeed, a genome-wide approach led to the discovery of an allelic variant in PRDM1 (also known as BLIMP1), a gene that predisposes Hodgkin lymphoma survivors to radiogenic cancer (71). As parallel approaches, wholegenome (72) or exon-based sequencing technologies could prove equally informative. The ongoing development of radiogenomics consortia (73) with annotated biospecimens is anticipated to provide additional data with regard to genetic variants that may increase the risk for radiogenic cancer.

The low frequencies of overtly pathogenic alleles, such as TP53 and $A T M$, suggest that they make a relatively small contribution at the population level. In addition, the heterogeneous patient responses to the acute and chronic effects of radiotherapy imply that these toxicities have complex genetic etiologies, rather than representing a monogenic trait. Furthermore, the fact that a single susceptibility locus with high-penetrance allelic variants for radiogenic cancer has not yet, to our knowledge, been identified further underscores the hypothesis that susceptibility to radiogenic cancer constitutes a polygenic trait, where cumulative risk is determined by co-inheritance of multiple low- and/or intermediate-penetrance "risk" alleles at several different loci, including, for example, PRDM1 (71). Understanding how multiple variants interact with each other and with radiation and phenotypic risk modifiers should be considered when developing risk prediction models to inform intervention strategies. Indeed, the inclusion of genetic data has substantially improved the accuracy of risk prediction models for SMNs or recurrence after head and neck cancer (74). Risk models that integrate genotypic, phenotypic, and treatment data and other variables should also be developed for Hodgkin lymphoma $(75,76)$ and other malignancies (5) where SMNs, CVD, and other late effects are important causes of morbidity and mortality.

An understanding of genetic and molecular factors that predispose individuals to the development of radiotherapy-induced cancers will also provide a foundation for the study of other late effects of radiation that have, in part, a known genetic basis, including CVD $(77,78)$. Although some genetic risk factors will undoubtedly 
be effect specific, the observation that some human diseases have overlapping transcriptional signatures in pathways such as lipid metabolism and carcinogenesis suggests that some pathways might apply to seemingly unrelated radiation-induced late effects, including cancer and CVD (79). Other pathways directly responsible for mediating cellular response to ionizing radiation are also likely to involve nonspecific risk factors. For example, radiation-induced reactive oxygen species can initiate an inflammatory response that leads to genomic instability and fibrosis, which have been implicated in the etiologies of cancer and CVD, respectively. In addition, Wethal et al. (80) showed that long-term survivors of testicular cancer with elevated serum levels of C-reactive protein, which is produced in response to inflammatory stimuli, had a two- to threefold increased risk of developing either SMN $(\mathrm{HR}=2.21 ; P<.05)$ or CVD $(\mathrm{HR}=2.79 ; P<.05)$.

\section{Radiotherapy Modalities, Technologies, and Dosimetry}

Technical innovations have changed the practice of radiotherapy (81). Modern anatomical imaging technologies provide threedimensional anatomical models of the patient that are often complemented with functional imaging studies such as positron emission tomography or magnetic resonance spectroscopy. Advanced imaging results in a more accurate determination of the tumor volumes and spatial relationships with the surrounding tissue and organs. Three-dimensional treatment planning systems, which take full advantage of these imaging advances, have facilitated the implementation of three-dimensional conformal radiation therapy as a standard of practice (81).

The development of medical linear accelerators equipped with computer-controlled multileaf collimator systems along with advanced computer-based treatment planning systems allow precise shaping of radiation dose distributions for each patient. Intensitymodulated radiation therapy (IMRT) can achieve even greater dose conformity through a computer-aided optimization process that creates a fluence of photons per radiation beam that is customized to the patient (82). The use of conformal radiation therapy has further evolved from IMRT to image-guided IMRT, also called image-guided radiation therapy. For very small tumor volumes adjacent to sensitive critical structures, cobalt-60 and linear accelerator-based stereotactic radiosurgery have been increasingly used in recent years, and new image-guided stereotactic body radiation therapy systems have been developed (83-86).

These advances have renewed interest in the use of protons for external beam radiotherapy (87). This technology allows conformal therapy to take advantage of the improved depth dose characteristics of the proton beam, which peak at the end of the range of the charged particle (87). In proton therapy, there are two techniques for beam production: passive scattering and beam scanning (87), with the latter method resulting in a lower amount of secondary neutrons.

The use of real-time imaging techniques to ensure the accuracy of new treatment modalities is increasing (88). Although the radiation dose from a single imaging technique is small compared with a therapeutic dose, repeated and daily image-guidance procedures can lead to cumulative exposures to normal tissues and possibly a slight increase in the risk of SMN (89). The transition from two-dimensional radiation therapy to three-dimensional conformal radiation therapy and/or IMRT has also resulted in changes in dose distribution compared with techniques used in prior SMN studies (90).

Advances in radiotherapy have also resulted in increased doses to normal tissue but an overall reduction in the volume of normal structures receiving high doses. However, especially with IMRT, a considerably larger volume of normal tissue within the irradiated field receives low doses. Because these doses outside the target field are much smaller than the tumor doses, they are generally not recorded in radiotherapy documentation nor are additional doses due to image-guided radiation therapy reported in medical records. This unwanted radiation leakage and scatter dose can be decreased through several designs, as reviewed elsewhere (91). It will be important for clinical trial quality assurance centers that monitor radiotherapy protocols to capture radiation doses to multiple organs outside radiation fields for those patients enrolled in advanced technology clinical trials to enable eventual correlation with late effects (91).

\section{SMNs Following Radiotherapy for Adult- Onset Cancer}

A sizable amount of SMN data has accrued for several adult-onset cancers in which radiotherapy has played pivotal roles, including Hodgkin lymphoma, non-Hodgkin lymphoma, and cancers of cervix, testis, breast, and prostate (14). The methods for estimating risk of SMNs from epidemiological data are described in Supplementary Material 1 (available online).

Hodgkin lymphoma survivors have elevated relative risks (RRs) for most SMNs (except bladder and prostate cancers), particularly breast and lung (90). Radiotherapy at a young age, especially before the age of 35 years, is associated with increased breast cancer risk (92-95), whereas treatment-related premature menopause is associated with decreased risk $(92,93,95,96)$. Both radiotherapy and alkylating chemotherapy have been associated with increased risks of lung cancer $(97,98)$. The risk of SMNs for pediatric Hodgkin lymphoma survivors appears to persist following low therapeutic doses of radiation and chemotherapy (99). Several case-control studies, some with detailed organ-specific dose reconstructions $(92,93,97,100,101)$, have reported statistically significant trends of increasing risks of breast $(92,93,100,102)$, lung $(97,103)$, and stomach (101) cancers with increasing radiation dose among several populations of survivors of adult-onset cancer.

Survivors of non-Hodgkin lymphoma are at increased risk for SMNs (104-115), and some of the increased risks are associated with radiotherapy. Radiotherapy for non-Hodgkin lymphoma has been linked to increased risks of acute leukemia $(111,116)$, bladder cancer $(104,105,110)$, kidney cancer (110), and mesothelioma $(90,107,117)$. The use of total body irradiation as part of transplantation approaches is associated with increased risks of acute leukemia and myelodysplastic syndrome (86,118-120) and solid tumors $(86,121,122)$, including breast cancer $(121)$.

Among testicular cancer survivors, past treatment with largefield radiotherapy is statistically significantly associated with the risk of leukemia; past treatment with infradiaphragmatic radiation 
is associated with a threefold increased non-statistically significant risk of leukemia (123). Statistically significant increased risks of cancers of the lung, thyroid, esophagus, stomach, pancreas, colon, rectum, kidney, bladder, and connective tissue have also been observed among long-term survivors of testicular cancer (124). These SMNs typically represent nontarget sites that were included in radiation fields (124). Concerns about radiation-related SMNs have prompted the adoption of observation-alone strategies following stage I seminoma (125).

Cancers associated with breast cancer radiotherapy include those of the contralateral breast (100,126-129), lung (126,130132), and esophagus (133), as well as sarcoma (134). The risk of contralateral breast cancer after radiotherapy for breast cancer appears to be limited to women who are younger than age 40-45 years at receipt of radiotherapy $(100,128,129)$ and is dose related (100). Risks for cancers of the lung and esophagus are higher after postmastectomy radiotherapy than after post lumpectomy radiotherapy $(130,132,133)$, likely reflecting the differing volumes of normal tissue in the treatment fields. Although the risk of sarcoma after breast cancer radiotherapy is increased compared with the risk of sarcoma in the general population, radiation-induced sarcoma remains a rare event (absolute risk $<0.5 \%$ at 15 years after radiotherapy) (134).

Kleinerman et al. (135) reported that radiotherapy for cervical cancer was associated with statistically significantly increased risks of cancers of bladder, kidneys, rectum, corpus uteri, and ovaries; these findings were confirmed in subsequent surveys (136-138). In the most recent update (139), the risks for several solid pelvic tumors remained statistically significantly elevated for more than 40 years after radiotherapy.

Some (140-143), but not all (144-146), studies have reported increased risks of colorectal cancer, bladder cancer, soft tissue sarcoma, and lung cancer among men treated with radiation for prostate cancer. The absolute risk of developing any SMN appeared modest (1 in 290 patients) (142), and some excess SMNs were detected incidentally during colonoscopies or cystoscopies.

\section{SMNs Following Radiotherapy for Childhood Cancer}

The risk of SMNs among childhood cancer survivors is associated with radiotherapy, chemotherapy, and genetic predisposition. In a recent CCSS update (6), the cumulative incidence of all subsequent neoplasms at 30 years after diagnosis was $20.5 \%$ (95\% confidence interval $[\mathrm{CI}]=19.1 \%$ to $21.8 \%$ ) among 5 -year survivors of childhood cancer treated from 1970 through 1986 and was higher for patients who received radiation therapy than for those who did not ( $25 \%$ vs $10 \%)$; radiation therapy exposure was associated with a statistically significantly increased risk of a subsequent neoplasm ( $\mathrm{RR}=2.7,95 \% \mathrm{CI}=2.2$ to 3.3$)$. Overall, cumulative incidence of SMNs at 30 years of follow-up was $7.9 \%$, and, again, was higher among patients who received radiotherapy than among those who did not receive radiotherapy $(\sim 10 \%$ vs $5 \%)$. Radiotherapy was associated with increased risks of secondary central nervous system tumors, bone and soft tissue sarcomas, thyroid cancer, and nonmelanoma skin cancer. A more recent CCSS report showed that, overall, patients who developed a second neoplasm had a cumulative incidence of developing yet another primary cancer by 20 years after the SMN of $46.9 \%$; the cumulative incidence of an additional primary cancer after an SMN was $41.3 \%$ among patients who received radiotherapy for the first cancer compared with $25.7 \%$ for those not treated with radiation; however, treatment for the SMN was not considered in these estimates (147). A study of 5 -year survivors of childhood solid tumors in Great Britain and France showed an association between integral radiation dose and risk of death from SMNs, with secondary carcinoma as the leading cause of death, followed by sarcoma and then hematological malignancies (148). Survivors of hereditary retinoblastoma have the highest risk of SMNs, with a cumulative incidence at 50 years after diagnosis of $36 \%$ (95\% CI $=31 \%$ to $41 \%$ ) compared with $5.7 \%$ (95\% CI $=2.4 \%$ to $11 \%)$ for survivors of nonhereditary retinoblastoma (32).

Among survivors of nonfamilial or hereditary malignancies, survivors of Hodgkin lymphoma appear to have the highest overall risk for SMNs. In a recent CCSS report of 2742 Hodgkin lymphoma survivors, of whom 94\% received radiation (149), the 30 -year cumulative incidence of any $\mathrm{SMN}$ was $10.9 \%(95 \% \mathrm{CI}=$ $8.3 \%$ to $13.4 \%$ ) in males and $26.1 \%$ ( $95 \%$ CI $=22.4 \%$ to $29.8 \%$ ) in females; the difference in cumulative incidence was due to invasive breast cancer (cumulative incidence $=18.3 \%$; $95 \% \mathrm{CI}=16.0 \%$ to $20.6 \%$ ). The highest absolute excess risks (excess cancers per 10000 person-years of follow-up) were observed for the following solid cancers: bone $=22.3(95 \% \mathrm{CI}=10.0$ to 49.6$)$, thyroid $=17.6$ $(95 \% \mathrm{CI}=13.0$ to 24.0$)$, and breast $=17.0(95 \% \mathrm{CI}=14.0$ to 21.7$)$. The median time from Hodgkin lymphoma diagnosis to diagnosis of invasive breast cancer was 21.0 years (range $=6.7-33.5$ years), with no apparent plateau.

The lower risk of SMN in survivors of childhood leukemia compared with survivors of childhood solid tumors is due to the less frequent use of radiotherapy in the former group $(6,148,150$ $155)$. The most frequent second neoplasms following radiotherapy for acute lymphoblastic leukemia are brain tumors, acute myeloid leukemia, and carcinomas of skin, thyroid, and parotid gland (150-154). The majority of late-onset radiation-associated second neoplasms in survivors of acute lymphoblastic leukemia are lowgrade (ie, meningiomas and basal cell carcinomas) $(154,156)$.

The risk of a radiation-associated brain tumor in survivors of childhood cancer is positively associated with young age at time of radiation ( $<6$ years), higher radiation dose ( $>30 \mathrm{~Gy}$ ), and concomitant treatment with antimetabolites (especially in patients with thiopurine methyltransferase deficiency) or growth hormone (157-160). In the Berlin-Frankfurt-Münster trials, which involved multimodal intensive therapy that includes chemotherapy and radiation $(151,161)$, the 15 -year cumulative risk of SMNs was $1.7 \%(95 \% \mathrm{CI}=0.1 \%$ to $3.4 \%)$ among patients treated with 12-Gy cranial irradiation, which was lower, albeit not statistically significantly, compared with a 15 -year cumulative risk of $3.2 \%(95 \% \mathrm{CI}=1.1 \%$ to $5.3 \%)$ for those receiving at least $18 \mathrm{~Gy}$. The markedly reduced use of prophylactic cranial irradiation in contemporary clinical trials for pediatric leukemia is anticipated to reduce the occurrence of SMNs. Indeed, the 10-year cumulative risk of SMNs ranged from only $0.1 \%(\mathrm{SE}=0.1 \%)$ to $3.3 \%$ $(\mathrm{SE}=1.2 \%)$ in patients treated for leukemia in the 1990s (162) 
and was particularly low (ie, $0.1 \%$ and $0.3 \%$ ) in the two studies that did not use cranial irradiation $(163,164)$.

\section{SMNs With Radiation Dose-Response Relationships}

Table 1 summarizes epidemiological studies of SMNs following radiotherapy that included the estimated dose of radiation to the organ of interest. Most of these studies had a nested case-control design, and the relative risk parameter served as the primary risk measure.

Radiotherapy is associated with secondary leukemia $(138,167$, 168), and several studies have reported an attenuation of the risk of secondary leukemia at very high radiation doses. For example, in an international study of nearly 150000 women treated for cervical cancer, the risk of leukemia increased with increasing dose to active bone marrow up to approximately $4 \mathrm{~Gy}(\mathrm{RR} \sim 2.5)$ and then declined to approximately 1.5 at a dose of 17 Gy (138). In these studies $(138,167)$, secondary chronic lymphocytic leukemia was not associated with radiotherapy $(138,167)$.

Case-control studies of female breast cancer following treatment for Hodgkin lymphoma before age 30 years (92) and in childhood cancer survivors (165) provide evidence of a radiation dose-response relationship. In both studies, the risk of breast cancer increased with increasing radiation dose to the breast, reaching an odds ratio of 8 or more at doses of 40 Gy or more with no evidence of a downturn in the risk of breast cancer at the highest doses (Figure 1, A). A radiation dose to the ovary exceeding 5 Gy reduced the slope of the radiation dose-response relationship for breast cancer in women given chest radiotherapy, and alkylating agents also reduced the risk of breast cancer in Hodgkin lymphoma survivors. Several studies $(92,93,95,96)$ have shown that this latter effect is due to treatment-related premature menopause. Doseresponse relationships have been identified at lower doses (mainly doses $<5$ Gy) for contralateral breast cancer but only among patients diagnosed with a first breast cancer before the age of 45 years $(100,128,129)$.

An international study of lung cancer in survivors of Hodgkin lymphoma demonstrated a statistically significant radiation doseresponse relationship $(97,169)$. This radiation dose-response was well described by a linear relationship with a modeled risk of sevenfold at $40 \mathrm{~Gy}$; thus, lung cancer risk increased with increasing radiation dose (ie, a downturn in risk at the highest doses was not apparent). This finding implies that the lower radiation doses administered to treat Hodgkin lymphoma today will likely be associated with lower risks of lung cancer. Elevated risk was apparent 5-9 years after radiation treatment and persisted for at least 20 years. The combined effect of radiation dose and therapy with alkylating agents was additive, whereas the combined effect of radiation and smoking was more than additive $(P<.001)$ and consistent with a multiplicative relationship.

There are few data on the relationship between radiation dose incidentally received by active bone marrow in the course of cancer treatment and subsequent leukemia risk. Kaldor et al. (170) found that among 11 Hodgkin lymphoma survivors who developed leukemia, the risk of leukemia in those who had received more than
20 Gy to the bone marrow was seven times larger than in those who had received smaller doses.

Information regarding radiation dose-response relationships and subsequent tumors of the central nervous system is sparse. Neglia et al. (157) found statistically significant radiation doseresponse relationships for both gliomas and meningiomas in childhood cancer survivors, and the relative risks at a given dose were higher for meningiomas than for gliomas (Figure 1, B). In a casecontrol study of childhood cancer survivors (166), the risk of thyroid cancer increased with increasing dose to approximately 29 Gy $(\mathrm{RR} \sim 10)$ and then decreased for doses of 30 Gy or higher (Figure 1, C).

Increased risks of bone cancer and soft tissue sarcomas have been reported in many patient populations that received therapeutic doses exceeding 10 Gy $(31,137,171)$. Especially, high relative risks of these SMNs have been observed among childhood cancer survivors, and a genetic interaction has been demonstrated in retinoblastoma survivors (31). A large international case-control study of cervical cancer that provided dose-response curves for $16 \mathrm{SMNs}$ in addition to leukemia found statistically significant dose-response relationships at very high doses ( $\geq 30 \mathrm{~Gy}$ ) for cancers of the rectum and bladder and all female genital cancers (137).

\section{CVD in Patients Who Received Radiation Therapy}

Radiation, chemotherapy, and biological agents, independently and in combination, increase the risk of CVD in cancer survivors. For survivors of some cancers, radiotherapy-related CVD is the leading noncancer cause of mortality $(93,170,172-175)$. Radiationrelated CVD includes pericardial disease, coronary artery disease, valvular dysfunction, conduction abnormalities, and cerebrovascular disease. However, the risk of pericarditis is rare with modern techniques of irradiation and dose fractionation. When at least $60 \%$ of the heart is irradiated at doses of 40 Gy or less, the risk for mild pericarditis is less than $5 \%$, and severe pericarditis is rare (176).

Coronary artery disease results from injury and replacement of damaged cells by myofibroblasts and the deposition of platelets, followed by a cascade of events that result in atherosclerosis (102). Myocardial infarction is one of the most common types of CVD in long-term Hodgkin lymphoma survivors. High-dose (ie, >30-35 Gy) mediastinal radiation, particularly in younger Hodgkin lymphoma patients, increases the risk of coronary artery disease $(177,178)$. The resulting high rate of complications and/or death most frequently occurs in Hodgkin lymphoma patients who have diastolic dysfunction (179). Among 2232 consecutive Hodgkin lymphoma patients treated from 1960 through 1991, irradiated children and adolescents had a markedly increased risk of death due to heart disease $(R R=28-37)$, and all of these deaths were in patients who received doses of 42-45 Gy (180). When this analysis was extended to include all Hodgkin lymphoma patients, the overall relative risk of death from acute myocardial infarction was 3.2 (180). The increased risks of death from myocardial infarction were statistically significant within 5 years after radiotherapy, the average time from completion of radiotherapy to myocardial infarction was 10.3 


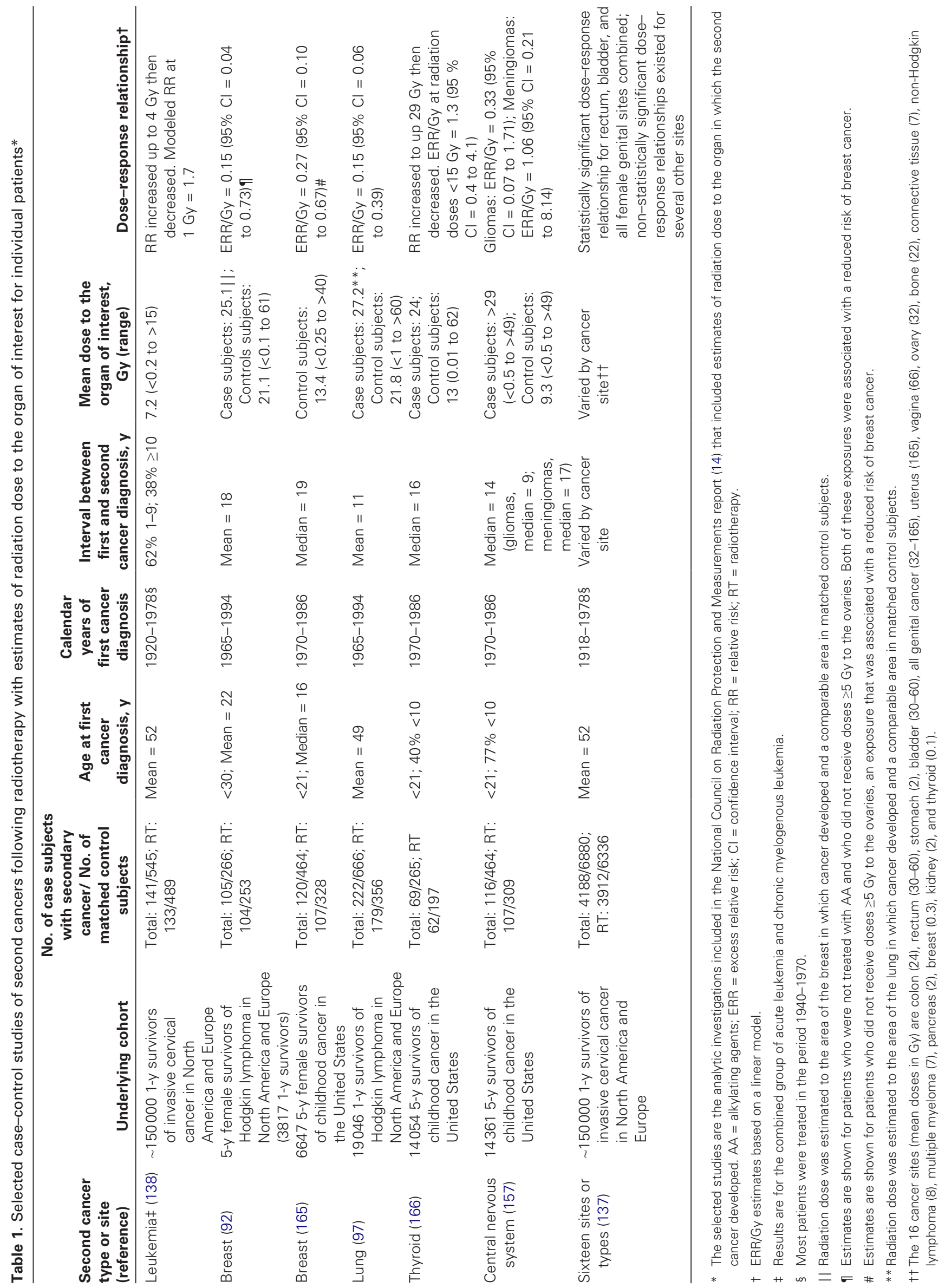


A

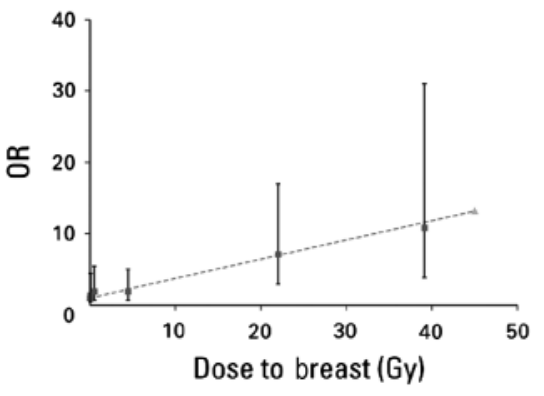

B

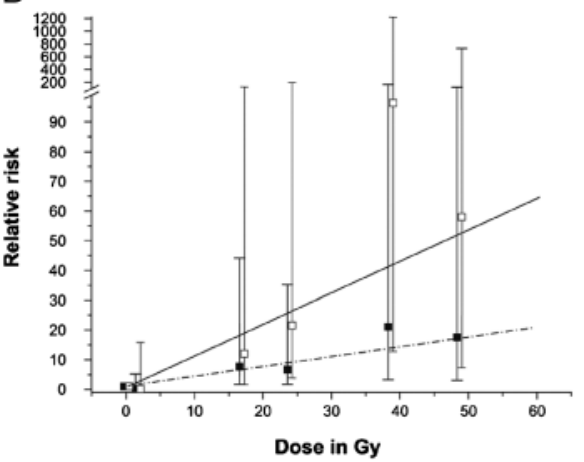

C

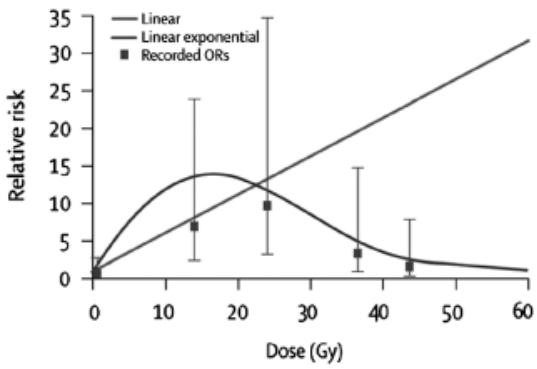

Figure 1. Selected cancer risks by radiation dose. A) Breast cancer risk according to radiation dose to the breast. From Inskip et al. (165). Reprinted with permission. Copyright 2008 American Society of Clinical Oncology. All rights reserved. B) Relative risk of subsequent glioma and meningioma within the Childhood Cancer Survivor Study cohort by radiation dose (open boxes, mean observed relative risk for meningioma; closed boxes, mean observed relative risk for glioma; solid line, fitted line for meningioma risk; hatched line, fitted line for glioma risk). $P<.001$ (likelihood ratio test, two-sided). From Neglia et al. (157). Reprinted with permission from Oxford University Press. C) Thyroid cancer risk by radiation dose in case subjects and control subjects after adjustment for first cancer. From Sigurdson et al. (166). Reprinted from Lancet 2005;365:2014-2023, with permission from Elsevier. Error bars represent $95 \%$ confidence intervals. ORs = odds ratios. years, and the risk of death from myocardial infarction remained elevated throughout the follow-up period (>20 years).

Many studies of breast cancer survivors have reported a statistically significant increase in coronary artery disease and/or nonfatal myocardial infarction associated with left-sided radiotherapy compared with right-sided radiotherapy or no radiotherapy (181-187). Breast cancer patients treated with internal mammary node radiotherapy may also be at increased risk for coronary artery disease (129, 182,188).

Radiotherapy is associated with an increased risk of valvular dysfunction $(189,190)$. Hull et al. (191) reported that valvular dysfunction developed in 25 of 415 Hodgkin lymphoma survivors at a median of 22 years after radiotherapy. In a large Dutch study of breast cancer survivors (184), the hazard ratio of valvular dysfunction for internal mammary node radiotherapy vs no radiotherapy was 3.17 (95\% CI $=1.90$ to 5.29$)$. The 2009 CCSS survey (9) showed that the cumulative incidence of self-reported valvular disease increased with increasing cardiac radiation dose.

Radiation may cause fibrosis of cardiac conduction pathways, which can lead to life-threatening arrhythmias or other conduction defects. Serious post-radiation abnormalities include atrioventricular nodal bradycardia, all levels of heart block including complete heart block, and sick sinus syndrome (192). The frequency of one type of cardiac conduction damage (ie, QTc $>0.44$ seconds) in 134 childhood cancer survivors was $12.5 \%$ after chest radiotherapy alone and $18.9 \%$ after radiotherapy and anthracyclines (192). Persistent fixed-rate tachycardia and loss of circadian variability in the heart rate have also been documented following chest radiotherapy that resulted in cardiac exposure. In one study (193), $74.5 \%$ of long-term survivors of Hodgkin lymphoma treated with chest radiotherapy had a cardiac conduction defect or arrhythmia, 31\% had sustained tachycardia, and $57 \%$ had a monotonous heart rate. Autonomic nervous system dysfunction
Figure 2. Cumulative incidence of cardiac disorders among childhood cancer survivors by average cardiac radiation dose. From Mulrooney et al. (9), with permission from BMJ Publishing Group Ltd. cGy = centigray.
Congestive heart failure
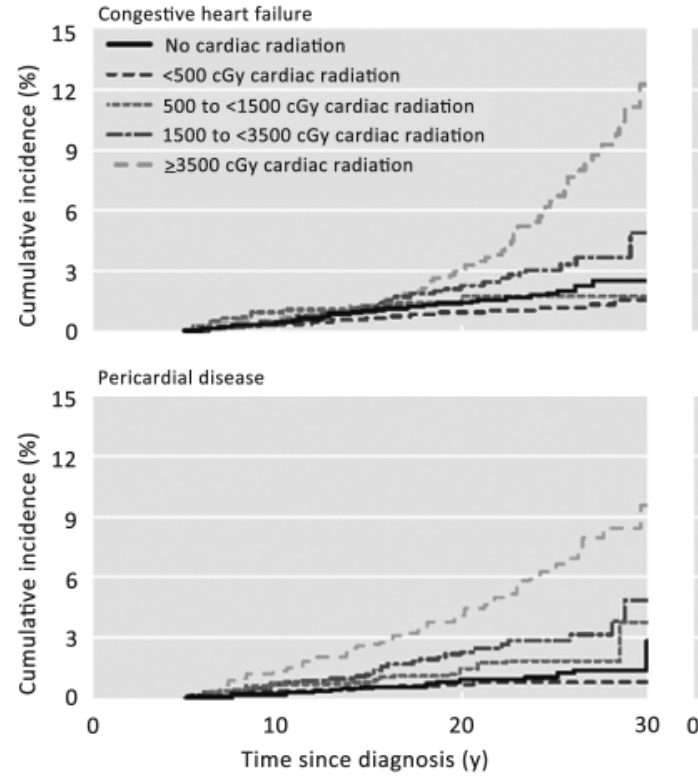

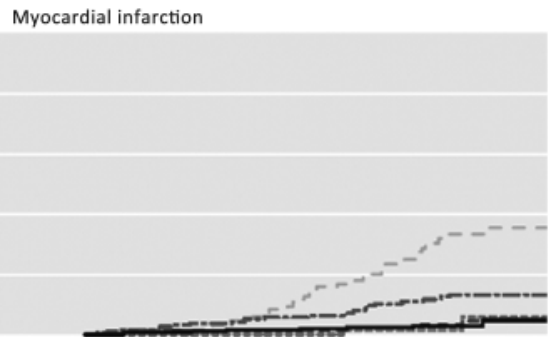

Valvular disease

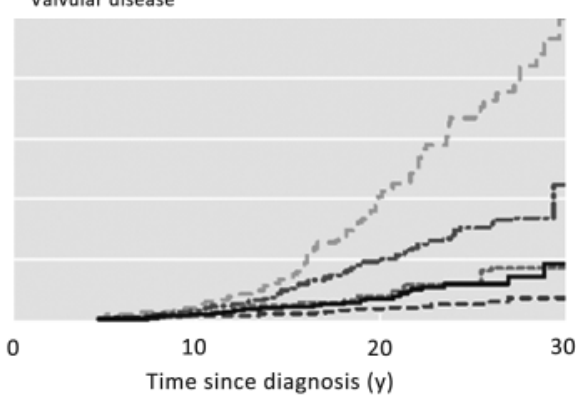


could lead to the decreased perception of angina observed by some patients.

Myocardial infarction due to radiotherapy can also lead to congestive heart failure. When myocardial dysfunction develops after standard-dose mediastinal irradiation, it is typically mild or subclinical (194) and involves diastolic and systolic left ventricular dysfunction (195). Restrictive cardiomyopathy is more common in cancer survivors treated with radiotherapy who have not received an anthracycline (196). Subtle left ventricular dysfunction has been detected by echocardiography and radionuclide angiography in Hodgkin lymphoma patients evaluated a few years after mediastinal irradiation (197). Two retrospective studies $(184,188)$ of congestive heart failure among irradiated breast cancer patients yielded conflicting results. A multi-institutional study with a median follow-up of 18 years found an increased risk of congestive heart failure with radiotherapy compared with no radiotherapy

Box 1. Conclusions and research recommendations of the NCRP 1-17 Report (14): Second Primary Cancers and Cardiovascular Disease after Radiotherapy*

\section{Conclusions}

1. Second primary cancers and cardiovascular disease after radiotherapy (RT) experienced by an ever-growing number of cancer survivors, with the most data accrued for second malignant neoplasms (SMNs).

2. Quantitative estimates of radiation-induced SMNs are: a) derived from studies incorporating comprehensive dose reconstructions; and b) although based on past regimens, are applicable to risk assessment following current RT in terms of organ-specific doses and dose-response relationships.

3. Newer RT modalities and treatment techniques, which include intensity-modulated radiotherapy (IMRT) and protons, result in different organ dose distributions.

4. Computational models are useful for SMN risk assessment and comparisons with older RT modalities; similar models to evaluate CVD should be developed.

5. Low-dose cardiac exposures have not been convincingly linked to CVD, but associations between CVD and whole-body doses of $<1 \mathrm{~Gy}$ among atomic bomb survivors are of potential clinical importance because many RT-treated patients receive low-dose cardiac doses from scatter and collimator leakage.

6. Few reports describe survival after SMN or CVD.

7. For individual and epidemiological risk assessment, the effective dose (a construct for radiation protection purposes) should not be used. Instead, the organ-specific absorbed dose coupled with the appropriate relative biological effectiveness for endpoint of interest and radiation type (eg, electrons, protons, neutrons) should be used for risk assessment.

\section{Research Recommendations}

1. Overarching recommendations

a. Long-term large-scale follow-up of extant cancer survivors to characterize the risks of SMNs and CVD and to evaluate role of comorbidities and effect modifiers.

b. Follow-up of prospective cohorts of cancer patients to evaluate life-long risks of SMNs, CVD, and other late effects, including

- Populations treated with newer RT modalities (including IMRT, tomotherapy, stereotactic RT, Cyberknife, gamma knife, and protons).

- Cancer sites for which reductions in field size and radiation dose have been implemented (eg, Hodgkin lymphoma, testis cancer), and cancer populations not treated with radiation (eg, testis cancer patients treated with surgery) to define natural history and baseline risks.

- Collect biological samples for evaluation of genetic factors in survival and development of SMNs and CVD.

2. Specific recommendations:

a. Given the differing dose-response relationships for various SMNs, analytic studies should continue to address the relationship between dose and risk, with similar efforts undertaken for CVD.

b. Compare the risks of SMNs and CVD after different RT modalities.

c. Address interactions between RT and other risk factors for SMNs and CVD.

d. Particular attention should be given to adolescent and young adult cancer survivors, given the scarcity of data (200).

e. Molecular and genetic underpinnings:

- Investigate genetic contributions of RT-associated SMNs and CVD.

- Intensively study patients who develop two or more primary cancers likely associated with RT.

f. Risk prediction models

- Develop comprehensive risk prediction models for SMN and CVD to stratify patients into risk groups to customize follow-up strategies and develop evidence-based interventions.

* Before publication, NCRP reports undergo comprehensive review by an outside panel of experts, who provide substantive and critical comments that are then addressed by the report's co-authors. The revised report is then reviewed by all members of the NCRP (http://www.ncrponline.org/Members/Council.html) before final revision, publication and endorsement by the NCRP. 
(184), whereas another investigation (188) found no increased incidence of congestive heart failure associated with radiotherapy laterality or internal mammary node radiotherapy.

Few analytic data describe the relationship between radiation dose to the heart and adverse outcomes. The 2009 CCSS survey (9) is thus noteworthy for the detailed dose-response evaluations conducted following radiotherapy and anthracycline treatments and the risks (albeit self-reported) of congestive heart failure, myocardial infarction, pericardial disease, and valvular abnormalities (Figure 2). Compared with siblings, childhood cancer survivors were statistically significantly more likely to report congestive heart failure $(\mathrm{HR}=5.9,95 \% \mathrm{CI}=3.4$ to 9.6$)$, myocardial infarction $(\mathrm{HR}=5.0,95 \% \mathrm{CI}=2.3$ to 10.4$)$, pericardial disease $(\mathrm{HR}=6.3$, $95 \% \mathrm{CI}=3.3$ to 11.9$)$, and valvular abnormalities $(\mathrm{HR}=4.8,95 \%$ $\mathrm{CI}=3.0$ to 7.6 ). Cardiac radiation exposure of at least $15 \mathrm{~Gy}$ increased the risk of congestive heart failure, myocardial infarction, pericardial disease, and valvular abnormalities by two- to sixfold compared with nonirradiated survivors. There was no evidence for increased risks of any of these conditions following exposure to less than 5 Gy, and the slight elevations in these risks were not statistically significant at exposures between 5 and 15 Gy. The hazard ratios for the four cardiac conditions ranged from 3.6 to 5.5 for cardiac doses greater than $35 \mathrm{~Gy}$. The cumulative incidence of adverse cardiac outcomes in childhood cancer survivors continued to increase up to 30 years after diagnosis and ranged from approximately $2 \%$ to slightly more than $4 \%$ overall, but to much higher levels for those who received the highest cardiac radiation doses (Figure 2) and the highest cumulative dose of anthracyclines. Recent data from the German-Austrian DAL-HD (German Association for Childhood Leukemia Research and Treatment and Hodgkin's disease) studies show a dose-response relationship for cardiac diseases in children treated for Hodgkin lymphoma with combined anthracycline-based chemotherapy (cumulative doxorubicin dose was uniformly $160 \mathrm{mg} / \mathrm{m}^{2}$ ) and radiation (198). The 25 -year cumulative incidence of cardiac disease was $3 \%$ with no radiotherapy, $5 \%$ after $20 \mathrm{~Gy}, 6 \%$ after $25 \mathrm{~Gy}, 10 \%$ after $30 \mathrm{~Gy}$, and $21 \%$ after 36 Gy (198).

Patients treated for head and neck cancer with radiation doses of 40-70 Gy, and particularly with doses greater than $60 \mathrm{~Gy}$, have an elevated risk for stroke and occlusive carotid artery disease (199-201). In one study (201), the median time from radiotherapy to stroke diagnosis was 10.9 years (range $=1.3-21$ years). Another study (199) reported 66 cerebrovascular events among 2567 head and neck cancer patients who were treated with 30-66 Gy radiotherapy compared with only 12 events among 4119 nonirradiated patients (odds ratio $=9.0 ; P<.001$ ).

In a 2009 study of 22015 -year survivors of Hodgkin lymphoma (201), 96 patients developed cerebrovascular disease (55 had a stroke, 31 had a transient ischemic attack, and 10 had both) at a median age of 52 years. The standardized incidence ratio was 2.2 for stroke and 3.1 for transient ischemic attack. Radiation to the neck and mediastinum was an independent risk factor for ischemic cerebrovascular disease $(\mathrm{HR}=2.5,95 \% \mathrm{CI}=1.1$ to 5.6 compared with no radiotherapy).

The incidence of stroke in the CCSS cohort was almost 10-fold higher than in the sibling comparison group (202). Leukemia survivors were six times more likely to suffer a stroke compared with the siblings, and brain tumor survivors were 29 times more likely. Of the brain tumor cohort, 69 (4.9\%) of 1411 patients who had a history of radiotherapy reported a stroke, and the cumulative incidence of stroke at 25 years after radiation therapy was $6.9 \%(95 \% \mathrm{CI}=4.5 \%$ to $9.3 \%)$. Cancer survivors who were exposed to cranial radiotherapy at a dose of 30 Gy or higher had an increased risk for stroke, with the highest risk among those treated with a dose of 50 Gy or higher (202). Adult survivors of childhood Hodgkin lymphoma who were treated with thoracic radiotherapy (median dose $=40 \mathrm{~Gy}$ ), which included mediastinal and neck radiotherapy, had a 5.6-fold increased risk of stroke compared with the siblings.

\section{Conclusions and Research Recommendations}

The conclusions and recommendations of the NCRP (14) are summarized in Box 1 and reproduced in their entirety in the Supplementary Material 2 (available online). The reader is referred to the NCRP report (14) for in-depth discussion of each of the conclusions and recommendations. In summary, although modern therapies prolong the lives of cancer patients, this success carries an increased risk of late adverse health effects, including SMNs and CVD. Awareness, evaluation, counseling, and amelioration strategies are recommended (14).

\section{References}

1. Altekruse SF, Kosary CL, Krapcho M, et al. SEER Cancer Statistics Review, 1975-2007. http://seer.cancer.gov/csr/1975_2007/. Accessed October 4, 2010.

2. Ringborg U, Bergqvist D, Brorsson B, et al. The Swedish Council on Technology Assessment in Health Care (SBU) systematic overview of radiotherapy for cancer including a prospective survey of radiotherapy practice in Sweden 2001-summary and conclusions. Acta Oncol. 2003; 42(5-6):357-365.

3. Ng AK, Bernardo MP, Weller E, et al. Long-term survival and competing causes of death in patients with early-stage Hodgkin's disease treated at age 50 or younger. 7 Clin Oncol. 2002;20(8):2101-2108.

4. van den Belt-Dusebout AW, de Wit R, Gietema JA, et al. Treatmentspecific risks of second malignancies and cardiovascular disease in 5 -year survivors of testicular cancer. 7 Clin Oncol. 2007;25(28):4370-4378.

5. Travis LB, Beard C, Allan JM, et al. Testicular cancer survivorship: research strategies and recommendations. I Natl Cancer Inst. 2010;102(15): 1114-1130.

6. Friedman DL, Whitton J, Leisenring W, et al. Subsequent neoplasms in 5-year survivors of childhood cancer: the Childhood Cancer Survivor Study. 7 Natl Cancer Inst. 2010;102(14):1083-1095.

7. Travis LB, Bhatia S, Allan JM, et al. Management of adverse effects of treatment: second primary cancers. In: DeVita VT Jr, Lawrence TS, Rosenberg SA, eds. Cancer: Principles and Practice of Oncology. 9th ed. Philadelphia, PA: Lippincott, Williams, and Wilkins; 2011;2393-2410.

8. Yahalom J, Portlock CS. Long-term cardiac and pulmonary complications of cancer therapy. Hematol Oncol Clin North Am. 2008;22(2):305318 , vii.

9. Mulrooney DA, Yeazel MW, Kawashima T, et al. Cardiac outcomes in a cohort of adult survivors of childhood and adolescent cancer: retrospective analysis of the Childhood Cancer Survivor Study cohort. BMF. 2009; 339:b4606.

10. NCI. Cancer Epidemiology Cohorts: Core Infrastructure and Methodological Research. http://epi.grants.cancer.gov/funding/cohorts/. Accessed September 28, 2010.

11. Robison LL, Armstrong GT, Boice JD, et al. The Childhood Cancer Survivor Study: a National Cancer Institute-supported resource for outcome and intervention research. F Clin Oncol. 2009;27(14):2308-2318. 
12. Travis LB, Rabkin CS, Brown LM, et al. Cancer survivorship-genetic susceptibility and second primary cancers: research strategies and recommendations. 7 Natl Cancer Inst. 2006;98(1):15-25.

13. Bhatia S, Robison LL. Cancer survivorship research: opportunities and future needs for expanding the research base. Cancer Epidemiol Biomarkers Prev. 2008;17(7):1551-1557.

14. National Council on Radiation Protection and Measurements (NCRP) Scientific Committee 1-17. Second Primary Cancers and Cardiovascular Disease After Radiotherapy. NCRP Report No. 170. Bethesda, MD: National Council on Radiation Protection and Measurements.

15. Little JB. Radiation carcinogenesis. Carcinogenesis. 2000;21(3):397-404.

16. UNSCEAR. Non-Targeted and Delayed Effects of Exposure to Ionizing Radiation. Annex C. New York, NY: Annex C, United Nations. 2009.

17. Averbeck D. Does scientific evidence support a change from the LNT model for low-dose radiation risk extrapolation? Health Phys. 2009; 97(5):493-504.

18. Kennedy AR. Factors that modify radiation-induced carcinogenesis. Health Phys. 2009;97(5):433-445.

19. Fry RJM, Ley RR. Ultraviolet radiation carcinogenesis. In: Slaga TJ, ed. Mechanisms of Tumor Promotion. Boca Raton, FL: CRC Press; 1984:73-96.

20. Burns FJ, Tang MS, Frenkel K, et al. Induction and prevention of carcinogenesis in rat skin exposed to space radiation. Radiat Environ Biophys. 2007;46(2):195-199.

21. Kennedy AR, Davis JG, Carlton W, et al. Effects of dietary antioxidant supplementation on the development of malignant lymphoma and other neoplastic lesions in mice exposed to proton or iron-ion radiation. Radiat Res. 2008;169(6):615-625.

22. Nutting C, Camplejohn RS, Gilchrist R, et al. A patient with 17 primary tumours and a germ line mutation in TP53: tumour induction by adjuvant therapy? Clin Oncol (R Coll Radiol). 2000;12(5):300-304.

23. Limacher JM, Frebourg T, Natarajan-Ame S, et al. Two metachronous tumors in the radiotherapy fields of a patient with $\mathrm{Li}$-Fraumeni syndrome. Int 7 Cancer. 2001;96(4):238-242.

24. Talwalkar SS, Yin CC, Naeem RC, et al. Myelodysplastic syndromes arising in patients with germline TP53 mutation and Li-Fraumeni syndrome. Arch Pathol Lab Med. 2010;134(7):1010-1015.

25. Sharif S, Ferner R, Birch JM, et al. Second primary tumors in neurofibromatosis 1 patients treated for optic glioma: substantial risks after radiotherapy. 7 Clin Oncol. 2006;24(16):2570-2575.

26. Little MP, de Vathaire F, Shamsaldin A, et al. Risks of brain tumour following treatment for cancer in childhood: modification by genetic factors, radiotherapy and chemotherapy. Int 7 Cancer. 1998;78(3): 269-275.

27. Wallin JL, Tanna N, Misra S, et al. Sinonasal carcinoma after irradiation for medulloblastoma in nevoid basal cell carcinoma syndrome. $\mathrm{Am}$ 7 Otolaryngol. 2007;28(5):360-362.

28. Bassal M, Mertens AC, Taylor L, et al. Risk of selected subsequent carcinomas in survivors of childhood cancer: a report from the Childhood Cancer Survivor Study. 7 Clin Oncol. 2006;24(3):476-483.

29. Henderson TO, Whitton J, Stovall M, et al. Secondary sarcomas in childhood cancer survivors: a report from the Childhood Cancer Survivor Study. f Natl Cancer Inst. 2007;99(4):300-308.

30. Breslow NE, Lange JM, Friedman DL, et al. Secondary malignant neoplasms after Wilms tumor: an international collaborative study. Int $\mathcal{F}$ Cancer. 2010;127(3):657-666.

31. Wong FL, Boice JD Jr., Abramson DH, et al. Cancer incidence after retinoblastoma. Radiation dose and sarcoma risk. $7 A M A$. 1997;278(15): 1262-1267.

32. Kleinerman RA, Tucker MA, Tarone RE, et al. Risk of new cancers after radiotherapy in long-term survivors of retinoblastoma: an extended follow-up. $\mathcal{F}$ Clin Oncol. 2005;23(10):2272-2279.

33. Pazzaglia S, Mancuso M, Tanori M, et al. Modulation of patched-associated susceptibility to radiation induced tumorigenesis by genetic background. Cancer Res. 2004;64(11):3798-3806.

34. Pazzaglia S, Tanori M, Mancuso M, et al. Linking DNA damage to medulloblastoma tumorigenesis in patched heterozygous knockout mice. Oncogene. 2006;25(8):1165-1173.
35. Backlund MG, Trasti SL, Backlund DC, et al. Impact of ionizing radiation and genetic background on mammary tumorigenesis in p53-deficient mice. Cancer Res. 2001;61(17):6577-6582.

36. Chao RC, Pyzel U, Fridlyand J, et al. Therapy-induced malignant neoplasms in Nf1 mutant mice. Cancer Cell. 2005;8(4):337-348.

37. Bernstein JL, Haile RW, Stovall M, et al. Radiation exposure, the ATM Gene, and contralateral breast cancer in the women's environmental cancer and radiation epidemiology study. 7 Natl Cancer Inst. 2010;102(7): 475-483.

38. Graeser MK, Engel C, Rhiem K, et al. Contralateral breast cancer risk in BRCA1 and BRCA2 mutation carriers. 7 Clin Oncol. 2009;27(35): 5887-5892.

39. Nichols KE, Levitz S, Shannon KE, et al. Heterozygous germline ATM mutations do not contribute to radiation-associated malignancies after Hodgkin's disease. 7 Clin Oncol. 1999;17(4):1259.

40. Offit K, Gilad S, Paglin S, et al. Rare variants of ATM and risk for Hodgkin's disease and radiation-associated breast cancers. Clin Cancer Res. 2002;8(12):3813-3819.

41. Narod SA, Lubinski J, Ghadirian P, et al. Screening mammography and risk of breast cancer in BRCA1 and BRCA2 mutation carriers: a casecontrol study. Lancet Oncol. 2006;7(5):402-406.

42. Andrieu N, Easton DF, Chang-Claude J, et al. Effect of chest X-rays on the risk of breast cancer among BRCA1/2 mutation carriers in the international BRCA1/2 carrier cohort study: a report from the EMBRACE, GENEPSO, GEO-HEBON, and IBCCS Collaborators' Group. 7 Clin Oncol. 2006;24(21):3361-3366.

43. Berrington de Gonzalez A, Berg CD, Visvanathan K, et al. Estimated risk of radiation-induced breast cancer from mammographic screening for young BRCA mutation carriers. 7 Natl Cancer Inst. 2009;101(3):205-209.

44. Li X, Dumont P, Della Pietra A, et al. The codon 47 polymorphism in p 53 is functionally significant. 7 Biol Chem. 2005;280(25):24245-24251.

45. Angele S, Romestaing P, Moullan N, et al. ATM haplotypes and cellular response to DNA damage: association with breast cancer risk and clinical radiosensitivity. Cancer Res. 2003;63(24):8717-8725.

46. Gutierrez-Enriquez S, Fernet M, Dork T, et al. Functional consequences of ATM sequence variants for chromosomal radiosensitivity. Genes Chromosomes Cancer. 2004;40(2):109-119.

47. Zhu F, Dolle ME, Berton TR. Mouse models for the p53 R72P polymorphism mimic human phenotypes. Cancer Res. 2010;70(14):5851-5859.

48. Rajaraman P, Bhatti P, Doody MM, et al. Nucleotide excision repair polymorphisms may modify ionizing radiation-related breast cancer risk in US radiologic technologists. Int 7 Cancer. 2008;123(11):2713-2716.

49. Schonfeld SJ, Bhatti P, Brown EE, et al. Polymorphisms in oxidative stress and inflammation pathway genes, low-dose ionizing radiation, and the risk of breast cancer among US radiologic technologists. Cancer Causes Control. 2010;21(11):1857-1866.

50. Sigurdson AJ, Bhatti P, Chang SC, et al. Polymorphisms in estrogen biosynthesis and metabolism-related genes, ionizing radiation exposure, and risk of breast cancer among US radiologic technologists. Breast Cancer Res Treat. 2009;118(1):177-184.

51. Sigurdson AJ, Bhatti P, Doody MM, et al. Polymorphisms in apoptosisand proliferation-related genes, ionizing radiation exposure, and risk of breast cancer among U.S. Radiologic Technologists. Cancer Epidemiol Biomarkers Prev. 2007;16(10):2000-2007.

52. Bhatti P, Struewing JP, Alexander BH, et al. Polymorphisms in DNA repair genes, ionizing radiation exposure and risk of breast cancer in U.S. Radiologic technologists. Int 7 Cancer. 2008;122(1):177-182.

53. Bhatti P, Doody MM, Rajaraman P, et al. Novel breast cancer risk alleles and interaction with ionizing radiation among U.S. radiologic technologists. Radiat Res. 2010;173(2):214-224.

54. Bhatti P, Doody MM, Alexander BH, et al. Breast cancer risk polymorphisms and interaction with ionizing radiation among U.S. radiologic technologists. Cancer Epidemiol Biomarkers Prev. 2008;17(8):2007-2011.

55. Lonn S, Bhatti P, Alexander BH, et al. Papillary thyroid cancer and polymorphic variants in TSHR- and RET-related genes: a nested case-control study within a cohort of U.S. radiologic technologists. Cancer Epidemiol Biomarkers Prev. 2007;16(1):174-177. 
56. Chang-Claude J, Ambrosone CB, Lilla C, et al. Genetic polymorphisms in DNA repair and damage response genes and late normal tissue complications of radiotherapy for breast cancer. Br $\mathcal{F}$ Cancer. 2009;100(10):1680-1686.

57. Chang-Claude J, Popanda O, Tan XL, et al. Association between polymorphisms in the DNA repair genes, XRCC1, APE1, and XPD and acute side effects of radiotherapy in breast cancer patients. Clin Cancer Res. 2005; 11(13):4802-4809.

58. Tan XL, Popanda O, Ambrosone CB, et al. Association between TP53 and p21 genetic polymorphisms and acute side effects of radiotherapy in breast cancer patients. Breast Cancer Res Treat. 2006;97(3):255-262.

59. De Ruyck K, Van Eijkeren M, Claes K, et al. TGFbeta1 polymorphisms and late clinical radiosensitivity in patients treated for gynecologic tumors. Int 7 Radiat Oncol Biol Phys. 2006;65(4):1240-1248.

60. Werbrouck J, De Ruyck K, Duprez F, et al. Acute normal tissue reactions in head-and-neck cancer patients treated with IMRT: influence of dose and association with genetic polymorphisms in DNA DSB repair genes. Int 7 Radiat Oncol Biol Phys. 2009;73(4):1187-1195.

61. Azria D, Ozsahin M, Kramar A, et al. Single nucleotide polymorphisms, apoptosis, and the development of severe late adverse effects after radiotherapy. Clin Cancer Res. 2008;14(19):6284-6288.

62. Burri RJ, Stock RG, Cesaretti JA, et al. Association of single nucleotide polymorphisms in SOD2, XRCC1 and XRCC3 with susceptibility for the development of adverse effects resulting from radiotherapy for prostate cancer. Radiat Res. 2008;170(1):49-59.

63. Kuptsova N, Chang-Claude J, Kropp S, et al. Genetic predictors of longterm toxicities after radiation therapy for breast cancer. Int 7 Cancer. 2008;122(6):1333-1339.

64. Yoshida K, Nakachi K, Imai K, et al. Lung cancer susceptibility among atomic bomb survivors in relation to CA repeat number polymorphism of epidermal growth factor receptor gene and radiation dose. Carcinogenesis. 2009;30(12):2037-2041.

65. Pugh TJ, Keyes M, Barclay L, et al. Sequence variant discovery in DNA repair genes from radiosensitive and radiotolerant prostate brachytherapy patients. Clin Cancer Res. 2009;15(15):5008-5016.

66. Sigurdson AJ, Land CE, Bhatti P, et al. Thyroid nodules, polymorphic variants in DNA repair and RET-related genes, and interaction with ionizing radiation exposure from nuclear tests in Kazakhstan. Radiat Res. 2009;171(1):77-88.

67. Zhang L, Yang M, Bi N, et al. ATM polymorphisms are associated with risk of radiation-induced pneumonitis. Int 7 Radiat Oncol Biol Phys. 2010; 77(5):1360-1368.

68. Zheng YL, Kosti O, Loffredo CA, et al. Elevated lung cancer risk is associated with deficiencies in cell cycle checkpoints: genotype and phenotype analyses from a case-control study. Int 7 Cancer. 2010;126(9):2199-2210.

69. Knight JA, Skol AD, Shinde A, et al. Genome-wide association study to identify novel loci associated with therapy-related myeloid leukemia susceptibility. Blood. 2009;113(22):5575-5582.

70. Ingle JN, Schaid DJ, Goss PE, et al. Genome-wide associations and functional genomic studies of musculoskeletal adverse events in women receiving aromatase inhibitors. 7 Clin Oncol. 2010;28(31):4674-4682.

71. Best T, Li D, Skol AD, et al. Variants at 6q21 implicate PRDM1 in the etiology of therapy-induced second malignancies after Hodgkin's lymphoma. Nat Med. 2011;17(8):941-943.

72. Cirulli ET, Goldstein DB. Uncovering the roles of rare variants in common disease through whole-genome sequencing. Nat Rev Genet. 2010;11(6):415-425

73. West C, Rosenstein BS, Alsner J. Establishment of a Radiogenomics Consortium. Int 7 Radiat Oncol Biol Phys. 2010;76(5):1295-1296.

74. Wu X, Spitz MR, Lee JJ, et al. Novel susceptibility loci for second primary tumors/recurrence in head and neck cancer patients: large-scale evaluation of genetic variants. Cancer Prev Res (Phila). 2009;2(7):617-624.

75. Travis LB, Hill D, Dores GM, et al. Cumulative absolute breast cancer risk for young women treated for Hodgkin lymphoma. 7 Natl Cancer Inst. 2005;97(19):1428-1437.

76. Longo DL. Radiation therapy in Hodgkin disease: why risk a Pyrrhic victory? 7 Natl Cancer Inst. 2005;97(19):1394-1395.
77. Hindorff LA, Sethupathy P, Junkins HA, et al. Potential etiologic and functional implications of genome-wide association loci for human diseases and traits. Proc Natl Acad Sci U S A. 2009;106(23):9362-9367.

78. NHGRI. A Catalog of Published Genome-Wide Association Studies. http://www. genome.gov/26525384. Accessed March 29, 2010.

79. Hirsch HA, Iliopoulos D, Joshi A, et al. A transcriptional signature and common gene networks link cancer with lipid metabolism and diverse human diseases. Cancer Cell. 2010;17(4):348-361.

80. Wethal T, Haugnes HS, Kjekshus J, et al. C-reactive protein; a potential marker of second cancer and cardiovascular disease in testicular cancer survivors? Eur 7 Cancer. 2010;46(18):3425-3433.

81. Purdy JA. From new frontiers to new standards of practice: advances in radiotherapy planning and delivery. In: Meyer JL, ed. IMRT, IGRT, SBRT-Advances in the Treatment Planning and Delivery of Radiotherapy. Basel, Switzerland: Karger; 2007:18-39.

82. Intensity Modulated Radiation Therapy Collaborative Working Group. Intensity-modulated radiotherapy: current status and issues of interest. Int 7 Radiat Oncol Biol Phys. 2001;51(4):880-914.

83. Leksell L. The stereotaxic method and radiosurgery of the brain. Acta Chir Scand. 1951;102(4):316-319.

84. Leksell L. Cerebral radiosurgery. I. Gammathalanotomy in two cases of intractable pain. Acta Chir Scand. 1968;134(8):585-595.

85. Lutz W, Winston KR, Maleki N. A system for stereotactic radiosurgery with a linear accelerator. Int 7 Radiat Oncol Biol Phys. 1988;14(2):373-381.

86. Brown JR, Yeckes H, Friedberg JW, et al. Increasing incidence of late second malignancies after conditioning with cyclophosphamide and totalbody irradiation and autologous bone marrow transplantation for nonHodgkin's lymphoma. 7 Clin Oncol. 2005;23(10):2208-2214.

87. Delaney TF, Kooy HM. Proton and Charged Particle Radiotherapy. Philadelphia, PA: Lippincott, Williams, and Wilkins; 2008.

88. Bortfeld T, Schmidt-Ullrich R, De Neve W, et al. Image-Guided IMRT. Berlin, Germany: Springer; 2005.

89. Hall EJ. Intensity-modulated radiation therapy, protons, and the risk of second cancers. Int 7 Radiat Oncol Biol Phys. 2006;65(1):1-7.

90. Hodgson DC, Gilbert ES, Dores GM, et al. Long-term solid cancer risk among 5-year survivors of Hodgkin's lymphoma. 7 Clin Oncol. 2007;25(12): 1489-1497.

91. Purdy JA. Dose to normal tissues outside the radiation therapy patient's treated volume: a review of different radiation therapy techniques. Health Pbys. 2008;95(5):666-676.

92. Travis LB, Hill DA, Dores GM, et al. Breast cancer following radiotherapy and chemotherapy among young women with Hodgkin disease. 7AMA. 2003;290(4):465-475.

93. van Leeuwen FE, Klokman WJ, Stovall M, et al. Roles of radiation dose, chemotherapy, and hormonal factors in breast cancer following Hodgkin's disease. 7 Natl Cancer Inst. 2003;95(13):971-980.

94. Ng AK, Bernardo MV, Weller E, et al. Second malignancy after Hodgkin disease treated with radiation therapy with or without chemotherapy: long-term risks and risk factors. Blood. 2002;100(6):1989-1996.

95. De Bruin ML, Sparidans J, van't Veer MB, et al. Breast cancer risk in female survivors of Hodgkin's lymphoma: lower risk after smaller radiation volumes. 7 Clin Oncol. 2009;27(26):4239-4246.

96. Basu SK, Schwartz C, Fisher SG, et al. Unilateral and bilateral breast cancer in women surviving pediatric Hodgkin's disease. Int 7 Radiat Oncol Biol Pbys. 2008;72(1):34-40.

97. Travis LB, Gospodarowicz M, Curtis RE, et al. Lung cancer following chemotherapy and radiotherapy for Hodgkin's disease. $7 \mathrm{Natl}$ Cancer Inst. 2002;94(3):182-192.

98. Swerdlow AJ, Schoemaker MJ, Allerton R, et al. Lung cancer after Hodgkin's disease: a nested case-control study of the relation to treatment. 7 Clin Oncol. 2001;19(6):1610-1618.

99. O'Brien MM, Donaldson SS, Balise RR, et al. Second malignant neoplasms in survivors of pediatric Hodgkin's lymphoma treated with low-dose radiation and chemotherapy. 7 Clin Oncol. 2010;28(7):1232-1239.

100. Stovall M, Smith SA, Langholz BM, et al. Dose to the contralateral breast from radiotherapy and risk of second primary breast cancer in the WECARE study. Int 7 Radiat Oncol Biol Phys. 2008;72(4):1021-1030. 
101. van den Belt-Dusebout AW, Aleman BM, Besseling G, et al. Roles of radiation dose and chemotherapy in the etiology of stomach cancer as a second malignancy. Int 7 Radiat Oncol Biol Phys. 2009;75(5):1420-1429.

102. Mauch P, Ng A, Aleman B, et al. Report from the Rockefellar Foundation Sponsored International Workshop on reducing mortality and improving quality of life in long-term survivors of Hodgkin's disease: July 9-16, 2003, Bellagio, Italy. Eur 7 Haematol Suppl. 2005;(66):68-76.

103. van Leeuwen FE, Klokman WJ, Stovall M, et al. Roles of radiotherapy and smoking in lung cancer following Hodgkin's disease. 7 Natl Cancer Inst. 1995;87(20):1530-1537.

104. Dores GM, Cote TR, Travis LB. New malignancies following Hodgkin lymphoma, non-Hodgkin lymphoma, and myeloma. In. New Malignancies Among Cancer Survivors: SEER Cancer Registries, 1973-2000. Bethesda, MD: National Cancer Institute; 2006; NIH Pub No. 05-5302.

105. Mudie NY, Swerdlow AJ, Higgins CD, et al. Risk of second malignancy after non-Hodgkin's lymphoma: a British Cohort Study. 7 Clin Oncol. 2006;24(10):1568-1574.

106. Sacchi S, Marcheselli L, Bari A, et al. Secondary malignancies after treatment for indolent non-Hodgkin's lymphoma: a 16-year follow-up study. Haematologica. 2008;93(3):398-404.

107. Tward JD, Wendland MM, Shrieve DC, et al. The risk of secondary malignancies over 30 years after the treatment of non-Hodgkin lymphoma. Cancer. 2006;107(1):108-115.

108. Landgren O, Pfeiffer RM, Stewart L, et al. Risk of second malignant neoplasms among lymphoma patients with a family history of cancer. Int 7 Cancer. 2007;120(5):1099-1102.

109. Travis LB, Weeks J, Curtis RE, et al. Leukemia following low-dose total body irradiation and chemotherapy for non-Hodgkin's lymphoma. 7 Clin Oncol. 1996;14(2):565-571.

110. Travis LB, Curtis RE, Glimelius B, et al. Bladder and kidney cancer following cyclophosphamide therapy for non-Hodgkin's lymphoma. 7 Natl Cancer Inst. 1995;87(7):524-530.

111. Travis LB, Curtis RE, Stovall M, et al. Risk of leukemia following treatment for non-Hodgkin's lymphoma. 7 Natl Cancer Inst. 1994;86(19): $1450-1457$.

112. Travis LB, Curtis RE, Glimelius B, et al. Second cancers among longterm survivors of non-Hodgkin's lymphoma. 7 Natl Cancer Inst. 1993; 85(23):1932-1937.

113. Travis LB, Holowaty E, Hunter V, et al. Acute basophilic leukemia and acute eosinophilic leukemia after therapy for non-Hodgkin's lymphoma. Am 7 Clin Pathol. 1993;100(2):186.

114. Travis LB, Gonzalez CL, Hankey BF, et al. Hodgkin's disease following non-Hodgkin's lymphoma. Cancer. 1992;69(9):2337-2342.

115. Travis LB, Curtis RE, Boice JD Jr., et al. Second cancers following nonHodgkin's lymphoma. Cancer. 1991;67(7):2002-2009.

116. Greene MH, Young RC, Merrill JM, et al. Evidence of a treatment dose response in acute nonlymphocytic leukemias which occur after therapy of non-Hodgkin's lymphoma. Cancer Res. 1983;43(4):1891-1898.

117. Teta MJ, Lau E, Sceurman BK, et al. Therapeutic radiation for lymphoma: risk of malignant mesothelioma. Cancer. 2007;109(7):1432-1438.

118. Pedersen-Bjergaard J, Andersen MK, Christiansen DH. Therapyrelated acute myeloid leukemia and myelodysplasia after high-dose chemotherapy and autologous stem cell transplantation. Blood. 2000;95(11): 3273-3279.

119. Hosing C, Munsell M, Yazji S, et al. Risk of therapy-related myelodysplastic syndrome/acute leukemia following high-dose therapy and autologous bone marrow transplantation for non-Hodgkin's lymphoma. Ann Oncol. 2002;13(3):450-459.

120. Metayer C, Curtis RE, Vose J, et al. Myelodysplastic syndrome and acute myeloid leukemia after autotransplantation for lymphoma: a multicenter case-control study. Blood. 2003;101(5):2015-2023.

121. Friedman DL, Rovo A, Leisenring $W$, et al. Increased risk of breast cancer among survivors of allogeneic hematopoietic cell transplantation: a report from the FHCRC and the EBMT-Late Effect Working Party. Blood. 2008;111(2):939-944.

122. Rizzo JD, Curtis RE, Socie G, et al. Solid cancers after allogeneic hematopoietic cell transplantation. Blood. 2009;113(5):1175-1183.
123. Travis LB, Andersson M, Gospodarowicz M, et al. Treatment-associated leukemia following testicular cancer. 7 Natl Cancer Inst. 2000;92(14): $1165-1171$.

124. Travis LB, Fossa SD, Schonfeld SJ, et al. Second cancers among 40,576 testicular cancer patients: focus on long-term survivors. 7 Natl Cancer Inst. 2005;97(18):1354-1365.

125. Chung P, Mayhew LA, Warde P, et al. Management of stage I seminomatous testicular cancer: a systematic review. Clin Oncol (R Coll Radiol). 2010; 22(1):6-16.

126. Kirova YM, Gambotti L, De Rycke Y, et al. Risk of second malignancies after adjuvant radiotherapy for breast cancer: a large-scale, single-institution review. Int $\mathcal{F}$ Radiat Oncol Biol Phys. 2007;68(2):359-363.

127. Hemminki K, Ji J, Forsti A. Risks for familial and contralateral breast cancer interact multiplicatively and cause a high risk. Cancer Res. 2007; 67(3):868-870.

128. Boice JD Jr, Harvey EB, Blettner M, et al. Cancer in the contralateral breast after radiotherapy for breast cancer. $N$ Engl 7 Med. 1992;326(12): 781-785.

129. Hooning MJ, Aleman BM, Hauptmann M, et al. Roles of radiotherapy and chemotherapy in the development of contralateral breast cancer. 7 Clin Oncol. 2008;26(34):5561-5568.

130. Zablotska LB, Neugut AI. Lung carcinoma after radiation therapy in women treated with lumpectomy or mastectomy for primary breast carcinoma. Cancer. 2003;97(6):1404-1411.

131. Deutsch M, Land SR, Begovic M, et al. The incidence of lung carcinoma after surgery for breast carcinoma with and without postoperative radiotherapy. Results of National Surgical Adjuvant Breast and Bowel Project (NSABP) clinical trials B-04 and B-06. Cancer. 2003;98(7):1362-1368.

132. Kaufman EL, Jacobson JS, Hershman DL, et al. Effect of breast cancer radiotherapy and cigarette smoking on risk of second primary lung cancer. 7 Clin Oncol. 2008;26(3):392-398.

133. Zablotska LB, Chak A, Das A, et al. Increased risk of squamous cell esophageal cancer after adjuvant radiation therapy for primary breast cancer. $\mathrm{Am}$ 7 Epidemiol. 2005;161(4):330-337.

134. Kirova YM, Vilcoq JR, Asselain B, et al. Radiation-induced sarcomas after radiotherapy for breast carcinoma: a large-scale single-institution review. Cancer. 2005;104(4):856-863.

135. Kleinerman RA, Curtis RE, Boice JD Jr, et al. Second cancers following radiotherapy for cervical cancer. 7 Natl Cancer Inst. 1982;69(5): 1027-1033.

136. Kleinerman RA, Boice JD Jr, Storm HH, et al. Second primary cancer after treatment for cervical cancer. An international cancer registries study. Cancer. 1995;76(3):442-452.

137. Boice JD Jr, Engholm G, Kleinerman RA, et al. Radiation dose and second cancer risk in patients treated for cancer of the cervix. Radiat Res. 1988; 116(1):3-55.

138. Boice JD Jr, Blettner M, Kleinerman RA, et al. Radiation dose and leukemia risk in patients treated for cancer of the cervix. 7 Natl Cancer Inst. 1987; 79(6):1295-1311.

139. Chaturvedi AK, Engels EA, Gilbert ES. Second cancers among 104,760 survivors of cervical cancer: evaluation of long-term risk. 7 Natl Cancer Inst. 2007;99(21):1634-1643.

140. Pickles T, Phillips N. The risk of second malignancy in men with prostate cancer treated with or without radiation in British Columbia, 1984-2000. Radiother Oncol. 2002;65(3):145-151.

141. Moon K, Stukenborg GJ, Keim J, et al. Cancer incidence after localized therapy for prostate cancer. Cancer. 2006;107(5):991-998.

142. Brenner DJ, Curtis RE, Hall EJ, et al. Second malignancies in prostate carcinoma patients after radiotherapy compared with surgery. Cancer. 2000;88(2):398-406.

143. Abdel-Wahab M, Reis IM, Wu J, et al. Second primary cancer risk of radiation therapy after radical prostatectomy for prostate cancer: an analysis of SEER data. Urology. 2009;74(4):866-871.

144. Kendal WS, Eapen L, Macrae R, et al. Prostatic irradiation is not associated with any measurable increase in the risk of subsequent rectal cancer. Int 7 Radiat Oncol Biol Phys. 2006;65(3):661-668. 
145. Chrouser K, Leibovich B, Bergstralh E, et al. Bladder cancer risk following primary and adjuvant external beam radiation for prostate cancer. f Urol. 2005;174(1):107-110; discussion 110-111.

146. Movsas B, Hanlon AL, Pinover W, et al. Is there an increased risk of second primaries following prostate irradiation? Int 7 Radiat Oncol Biol Phys. 1998;41(2):251-255.

147. Armstrong GT, Liu W, Leisenring W, et al. Occurrence of multiple subsequent neoplasms in long-term survivors of childhood cancer: a report from the childhood cancer survivor study. 7 Clin Oncol. 2011;29(22): 3056-3064.

148. Tukenova M, Guibout C, Hawkins M, et al. Radiation therapy and late mortality from second sarcoma, carcinoma, and hematological malignancies after a solid cancer in childhood. Int 7 Radiat Oncol Biol Phys. 2011;80(2):339-346.

149. Castellino SM, Geiger AM, Mertens AC, et al. Morbidity and mortality in long-term survivors of Hodgkin lymphoma: a report from the Childhood Cancer Survivor Study. Blood. 2011;117(6):1806-1816.

150. Bhatia S, Sather HN, Pabustan OB, et al. Low incidence of second neoplasms among children diagnosed with acute lymphoblastic leukemia after 1983. Blood. 2002;99(12):4257-4264.

151. Loning L, Zimmermann M, Reiter A, et al. Secondary neoplasms subsequent to Berlin-Frankfurt-Munster therapy of acute lymphoblastic leukemia in childhood: significantly lower risk without cranial radiotherapy. Blood. 2000;95(9):2770-2775.

152. Neglia JP, Friedman DL, Yasui Y, et al. Second malignant neoplasms in five-year survivors of childhood cancer: childhood cancer survivor study. 7 Natl Cancer Inst. 2001;93(8):618-629.

153. Pui $\mathrm{CH}$, Cheng $\mathrm{C}$, Leung W, et al. Extended follow-up of long-term survivors of childhood acute lymphoblastic leukemia. $N$ Engl 7 Med. 2003;349(7):640-649.

154. Hijiya N, Hudson MM, Lensing S, et al. Cumulative incidence of secondary neoplasms as a first event after childhood acute lymphoblastic leukemia. FAMA. 2007;297(11):1207-1215.

155. Leung W, Ribeiro RC, Hudson M, et al. Second malignancy after treatment of childhood acute myeloid leukemia. Leukemia. 2001;15(1):41-45.

156. Goshen Y, Stark B, Kornreich L, et al. High incidence of meningioma in cranial irradiated survivors of childhood acute lymphoblastic leukemia. Pediatr Blood Cancer,. 2007;49(3):294-297.

157. Neglia JP, Robison LL, Stovall M, et al. New primary neoplasms of the central nervous system in survivors of childhood cancer: a report from the Childhood Cancer Survivor Study. 7 Natl Cancer Inst. 2006;98(21): 1528-1537.

158. Walter AW, Hancock ML, Pui CH, et al. Secondary brain tumors in children treated for acute lymphoblastic leukemia at St Jude Children's Research Hospital. 7 Clin Oncol. 1998;16(12):3761-3767.

159. Relling MV, Rubnitz JE, Rivera GK, et al. High incidence of secondary brain tumours after radiotherapy and antimetabolites. Lancet. 1999; 354(9172):34-39.

160. Ergun-Longmire B, Mertens AC, Mitby P, et al. Growth hormone treatment and risk of second neoplasms in the childhood cancer survivor. 7 Clin Endocrinol Metab. 2006;91(9):3494-3498.

161. Schrappe M, Reiter A, Ludwig WD, et al. Improved outcome in childhood acute lymphoblastic leukemia despite reduced use of anthracyclines and cranial radiotherapy: results of trial ALL-BFM 90. German-AustrianSwiss ALL-BFM Study Group. Blood. 2000;95(11):3310-3322.

162. Pui $\mathrm{CH}$, Carroll WL, Meshinci S, et al. Biology, risk stratification and therapy of pediatric acute leukemias: an update. 7 Clin Oncol. 2011;29(5):551-565.

163. Pui CH, Campana D, Pei D, et al. Treating childhood acute lymphoblastic leukemia without cranial irradiation. N Engl F Med. 2009;360(26): 2730-2741.

164. Kamps WA, van der Pal-de Bruin KM, Veerman AJ, et al. Long-term results of Dutch Childhood Oncology Group studies for children with acute lymphoblastic leukemia from 1984 to 2004. Leukemia. 2010;24(2):309-319.

165. Inskip PD, Robison LL, Stovall M, et al. Radiation dose and breast cancer risk in the childhood cancer survivor study. 7 Clin Oncol. 2009;27(24): 3901-3907.
166. Sigurdson AJ, Ronckers CM, Mertens AC, et al. Primary thyroid cancer after a first tumour in childhood (the Childhood Cancer Survivor Study): a nested case-control study. Lancet. 2005;365(9476):2014-2023.

167. Curtis RE, Boice JD Jr, Stovall M, et al. Risk of leukemia after chemotherapy and radiation treatment for breast cancer. N Engl 7 Med. 1992; 326(26):1745-1751.

168. Curtis RE, Boice JD Jr, Stovall M, et al. Relationship of leukemia risk to radiation dose following cancer of the uterine corpus. 7 Natl Cancer Inst 1994;86(17):1315-1324.

169. Gilbert ES, Stovall M, Gospodarowicz M, et al. Lung cancer after treatment for Hodgkin's disease: focus on radiation effects. Radiat Res. 2003; 159(2):161-173.

170. Kaldor JM, Day NE, Clarke EA, et al. Leukemia following Hodgkin's disease. N Engl f Med. 1990;322(1):7-13.

171. Tucker MA, D'Angio GJ, Boice JD Jr, et al. Bone sarcomas linked to radiotherapy and chemotherapy in children. $N$ Engl $\mathcal{F}$ Med. 1987;317(10): 588-593.

172. Swerdlow AJ, Barber JA, Hudson GV, et al. Risk of second malignancy after Hodgkin's disease in a collaborative British cohort: the relation to age at treatment. 7 Clin Oncol. 2000;18(3):498-509.

173. Reulen RC, Winter DL, Frobisher C, et al. Long-term cause-specific mortality among survivors of childhood cancer. FAMA. 2010;304(2):172-179.

174. Applefeld MM, Cole JF, Pollock SH, et al. The late appearance of chronic pericardial disease in patients treated by radiotherapy for Hodgkin's disease. Ann Intern Med. 1981;94(3):338-341.

175. Ling LH, Oh JK, Schaff HV, et al. Constrictive pericarditis in the modern era: evolving clinical spectrum and impact on outcome after pericardiectomy. Circulation. 1999;100(13):1380-1386.

176. Stewart JR, Fajardo LF, Gillette SM, et al. Radiation injury to the heart. Int 7 Radiat Oncol Biol Phys. 1995;31(5):1205-1211.

177. Hancock SL, Donaldson SS, Hoppe RT. Cardiac disease following treatment of Hodgkin's disease in children and adolescents. 7 Clin Oncol. 1993; 11(7):1208-1215.

178. Aleman BM, van den Belt-Dusebout AW, De Bruin ML, et al. Late cardiotoxicity after treatment for Hodgkin lymphoma. Blood. 2007;109(5): 1878-1886.

179. Heidenreich PA, Hancock SL, Vagelos RH, et al. Diastolic dysfunction after mediastinal irradiation. Am Heart 7. 2005;150(5):977-982.

180. Hancock SL, Tucker MA, Hoppe RT. Factors affecting late mortality from heart disease after treatment of Hodgkin's disease. 7AMA. 1993; 270(16):1949-1955.

181. Borger JH, Hooning MJ, Boersma LJ, et al. Cardiotoxic effects of tangential breast irradiation in early breast cancer patients: the role of irradiated heart volume. Int 7 Radiat Oncol Biol Phys. 2007;69(4):1131-1138.

182. Correa CR, Litt HI, Hwang WT, et al. Coronary artery findings after left-sided compared with right-sided radiation treatment for early-stage breast cancer. 7 Clin Oncol. 2007;25(21):3031-3037.

183. Hojris I, Overgaard M, Christensen JJ, et al. Morbidity and mortality of ischaemic heart disease in high-risk breast-cancer patients after adjuvant postmastectomy systemic treatment with or without radiotherapy: analysis of DBCG $82 \mathrm{~b}$ and $82 \mathrm{c}$ randomised trials. Radiotherapy Committee of the Danish Breast Cancer Cooperative Group. Lancet. 1999;354(9188):1425-1430.

184. Hooning MJ, Botma A, Aleman BM, et al. Long-term risk of cardiovascular disease in 10-year survivors of breast cancer. 7 Natl Cancer Inst. 2007;99(5): $365-375$.

185. Paszat LF, Vallis KA, Benk VM, et al. A population-based case-cohort study of the risk of myocardial infarction following radiation therapy for breast cancer. Radiother Oncol. 2007;82(3):294-300.

186. Vallis KA, Pintilie M, Chong N, et al. Assessment of coronary heart disease morbidity and mortality after radiation therapy for early breast cancer. F Clin Oncol. 2002;20(4):1036-1042.

187. Hill-Kayser CE, Harris EE, Hwang WT, et al. Twenty-year incidence and patterns of contralateral breast cancer after breast conservation treatment with radiation. Int 7 Radiat Oncol Biol Phys. 2006;66(5):1313-1319.

188. Harris EE, Correa C, Hwang WT, et al. Late cardiac mortality and morbidity in early-stage breast cancer patients after breast-conservation treatment. 7 Clin Oncol. 2006;24(25):4100-4106. 
189. Carlson RG, Mayfield WR, Normann S, et al. Radiation-associated valvular disease. Chest. 1991;99(3):538-545.

190. Tamura A, Takahara Y, Mogi K, et al. Radiation-induced valvular disease is the logical consequence of irradiation. Gen Thorac Cardiovasc Surg. 2007; 55(2):53-56.

191. Hull MC, Morris CG, Pepine CJ, et al. Valvular dysfunction and carotid, subclavian, and coronary artery disease in survivors of Hodgkin lymphoma treated with radiation therapy. $7 A M A$. 2003;290(21): 2831-2837.

192. Orzan F, Brusca A, Gaita F, et al. Associated cardiac lesions in patients with radiation-induced complete heart block. Int 7 Cardiol. 1993;39(2):151-156.

193. Adams MJ, Lipsitz SR, Colan SD, et al. Cardiovascular status in long-term survivors of Hodgkin's disease treated with chest radiotherapy. 7 Clin Oncol. 2004;22(15):3139-3148.

194. Glanzmann C, Kaufmann P, Jenni R, et al. Cardiac risk after mediastinal irradiation for Hodgkin's disease. Radiother Oncol. 1998;46(1):51-62.

195. Cameron EH, Lipshultz SE, Tarbell NJ, et al. Cardiovascular disease in long-term survivors of pediatric Hodgkin's disease. Prog Pediatr Cardiol. 1998;8:139-144.

196. Tolba KA, Deliargyris EN. Cardiotoxicity of cancer therapy. Cancer Invest. 1999;17(6):408-422.

197. Marks LB, Yu X, Prosnitz RG, et al. The incidence and functional consequences of RT-associated cardiac perfusion defects. Int $\mathcal{F}$ Radiat Oncol Biol Phys. 2005;63(1):214-223.

198. Schellong G, Riepenhausen M, Bruch C, et al. Late valvular and other cardiac diseases after different doses of mediastinal radiotherapy for Hodgkin disease in children and adolescents: report from the longitudinal GPOH follow-up project of the German-Austrian DAL-HD studies. Pediatr Blood Cancer. 2010;55(6):1145-1152.

199. Scott AS, Parr LA, Johnstone PA. Risk of cerebrovascular events after neck and supraclavicular radiotherapy: a systematic review. Radiother Oncol. 2009;90(2):163-165.

200. Smith GL, Smith BD, Buchholz TA, et al. Cerebrovascular disease risk in older head and neck cancer patients after radiotherapy. 7 Clin Oncol. 2008;26(31):5119-5125.

201. De Bruin ML, Dorresteijn LD, van't Veer MB, et al. Increased risk of stroke and transient ischemic attack in 5-year survivors of Hodgkin lymphoma. 7 Natl Cancer Inst. 2009;101(13):928-937.

202. Bowers DC, Liu Y, Leisenring W, et al. Late-occurring stroke among long-term survivors of childhood leukemia and brain tumors: a report from the Childhood Cancer Survivor Study. 7 Clin Oncol. 2006;24(33): $5277-5282$.

\section{Funding}

Supported in part by grant CA21765 from the National Institutes of Health, the American Lebanese Syrian Associated Charities (C.-H.P), and the University of Rochester Medical Center (L.B.T.).

\section{Notes}

We wish to thank Ms Laura Atwell (NCRP) and Dr Charles Church (National Center for Physical Acoustics, University of Mississippi) for their support of NCRP Scientific Committee 1-17, as well as Dr Tom Tenforde (President, NCRP) and Dr David Schauer (Executive Director, NCRP). We are also indebted to Ms Laura Brumbaugh (URMC) for expert editorial assistance. The NCRP Committee was responsible for preparing the comprehensive report (upon which this commentary is based) with NCRP's financial support from the National Cancer Institute under Grant Number R24 CA074206. The funding agency had no role in design, analysis, or interpretation of the reviewed data; in the decision to submit the commentary for publication; or the writing of the commentary. The content of this commentary is the sole responsibility of the co-authors and does not necessarily reflect the views of the funding agency (NCI). The NCRP Scientific Committee 1-17 report will be available Spring 2012 at www.ncrponline.org.

Affiliations of authors: Rubin Center for Cancer Survivorship and Department of Radiation Oncology, James P. Wilmot Cancer Center, University of Rochester Medical Center, Rochester, NY (LBT, LSC); Department of Radiation Oncology, Brigham and Women's Hospital, Harvard Medical School, Boston, MA (AKN); Dana-Farber Cancer Institute, Boston, MA (AKN); Northern Institute for Cancer Research, Newcastle University, Newcastle upon Tyne, UK (JMA); Department of Oncology, St. Jude Children's Research Hospital, Memphis, TN (C-HP); the University of Tennessee Health Science Center, Memphis, TN (C-HP); Department of Radiation Oncology, University of Pennsylvania School of Medicine, Philadelphia, PA (ARK); Nuclear Engineering and Engineering Physics Program, Rensselaer Polytechnic Institute, Troy, NY (XGX); Department of Radiation Oncology, University of California at Davis, Davis, CA (JAP); Department of Radiology, Emory University, Atlanta, GA (KA); Department of Radiation Oncology, Memorial SloanKettering Cancer Center, New York, NY (JY); Division of Cancer Epidemiology and Genetics, National Cancer Institute, Bethesda, MD (ESG); Department of Medicine, Vanderbilt University, Nashville, TN (JDB); International Epidemiology Institute, Rockville, MD (JDB). 